\title{
Clostridium difficile infections in teaching hospital in northern Finland
}

\author{
M. Marttila-Vaara' ${ }^{1}$, P. Ylipalosaari ${ }^{2^{*}}$ (D) and H. Kauma ${ }^{1}$
}

\begin{abstract}
Background: The aim of this study to compare the incidence of Clostridium difficile (CD) infections in the five university hospital districts in Finland based on national register. The clinical findings of CD cases in the Oulu University Hospital (OUH) in one-year cohort were also analyzed.

Methods: The numbers of the CD cases from the national register were used for the hospital district comparison. A retrospective cohort study was conducted among all adult (> 16 years) patients treated in the OUH in 2013, who had positive CD toxin B gene test in stools. The selection of the cohort was based on the data from the OUH microbiology laboratory and the clinical characteristics were collected from hospital records.

Results: The incidence of CD findings in 2013 was higher in the OUH district than in the other four university hospital districts: 159 vs. 70 to 84 per 100,000 inhabitants.

In 2013, 261 patients had CD infection treated in the OUH. The yearly number of CD cases treated in the OUH in 2009-2016 varied between 221 and 287, and the corresponding proportion of positive CD findings out of all samples taken varied from 10.0 to $17.8 \%$. A recurrent infection was seen in 58 patients (22\%) while the all-cause 30 day mortality was $7.3 \%$.
\end{abstract}

Conclusions: Diagnostic strategies differed nationally, which may explain the differences in CD incidence between the university hospital districts. In the OUH, no increase in the number of CD infections was seen in 2009-2016. Main characteristics of the patient cohort in the OUH were in harmony with earlier literature.

Keywords: Diarrhea, Clostridium difficile, Healthcare associated infection, Epidemiology

\section{Background}

Clostridium difficile infection (CDI) is a leading cause of hospital -associated gastrointestinal illness which varies from of illness, which varies from asymptomatic infection, diarrhea, colitis, and pseudo-membranous colitis to death [1]. C. difficile expresses two key virulence factors; the exotoxins, toxin $\mathrm{A}(\mathrm{TcdA})$ and toxin $\mathrm{B}(\mathrm{TcdB})$, which are glucosyltransferases targeting host-cell monomeric GTPases [2]. In addition, some hypervirulent strains produce a third toxin, binary toxin or C. difficile transferase (CDT), which may contribute to the pathogenesis of CDI [3]. The innate immune responses to $C$. difficile and its toxins are very important in the pathogenesis of CDI, although the adaptive immune responses have also been reported to influenze the severity of CDI [4]. Diagnostic approaches are complex due

\footnotetext{
* Correspondence: pekka.ylipalosaari@ppshp.fi

${ }^{2}$ Department of Infection Control, Oulu University Hospital, Box PL 20

FIN-90029 OYS, Oulu, Finland

Full list of author information is available at the end of the article
}

to the availability of multiple testing strategies. Multistep algorithms using polymerase chain reaction (PCR) for the toxin gene(s) or single-step PCR on liquid stool samples have the best test performance characteristics [5].

Risk factors for $C$. difficile infection (CDI) have typically been recent antibiotic exposure, advanced age, use of proton pump inhibitor, length of stay in healthcare settings, serious underlying illness, and immunocompromised conditions [6, 7]. Patients with CDI typically have extended lengths of stay in hospitals, and CDI is a frequent cause of large hospital outbreaks. The cost of treatment is expensive and the financial burden on the medical system is substantial $[6,8]$. Earlier literature on this topic in Finland has been controversial. It has been suggested that the figures of health care associated CDI have decreased due to better infection control althought diagnostic methods have become more sensitive [9]. In the other study the level of fluoroquinolone use has been

(c) The Author(s). 2019 Open Access This article is distributed under the terms of the Creative Commons Attribution 4.0 International License (http://creativecommons.org/licenses/by/4.0/), which permits unrestricted use, distribution, and 
associated to regional differences of CDI [10]. We compare the incidence of CDI according to the National Infectious Diseases Register (NIDR, National Institute for Health and Welfare, Helsinki, Finland) in five university hospital districts in Finland. Moreover, we characterize CDI patients treated in the Oulu University Hospital (OUH) in one-year cohort.

\section{Methods}

The study was conducted in the Oulu University Hospital which is a tertiary care teaching hospital covering an area of approximately 407,000 inhabitants, with 985 beds and approx. 260,000 treatment days/ year. The incidence of $\mathrm{CD}$ findings in five university hospital districts in Finland was compared using the data of the National Infectious Diseases Register (NIDR) of National Institute for Health and Welfare in the year 2013 [11]. Noteworthy is that this register includes not just patients treated in the OUH but also patients treated in non-teaching hospitals, health centers and in private clinics in this district. Therefore the numbers of the cases treated in the $\mathrm{OUH}$ are clearly lower than cases in the whole OUH district.

The trend of $C$. difficile figures in the $\mathrm{OUH}$ the years 2010-2016 was analyzed according to the CD findings diagnosed in the microbiology laboratory of the OUH. The following data was collected from the hospital database: age, comorbidities, hospitalization history, antibiotic exposure, procedures, mortality data $(30 \mathrm{~d})$, CDI recurrences, and length of hospital stays. All cases underwent full medical-record review by an infectious diseases specialist (M. M-V.) to collect information on coexisting medical conditions, medication exposures, first laboratory-confirmed recurrences (i.e. positive specimen within 2 to 8 weeks after the last positive test). The term 'recurrent CDI' was used to denote either relapse or reinfection, as the diagnosis and management of both forms of recurrence are similar, and the two mechanisms are rarely differentiated in clinical practice.
The method for CDI detection was a polymerase chain reaction (PCR) -based, nucleic acid amplification test (NAAT) on CDI toxin B gene, $t c d B$, without preceding fecal culture. The samples were analyzed using GenomEra $\mathrm{CDX}^{\mathrm{im}}$ test (Abacus Diagnostica, Turku, Finland). The incidences of $C$. difficile in (CD) gene typing $\mathrm{CD}$ pathogenicity (PaLoc) and CDT locus virulence factors were tested using in-house multiplex PCR method, using gel electrophoresis to test for $t c d A$ and $t c d B$ whether there is toxin production and whether the regulatory elements of the genes are mutated, like with deletions (e.g. ribotype 027). [12] All samples with differing gene profiles were sent to the National Institute for Health and Welfare (THL, Turku, Finland) for further ribotyping.

\section{Statistical analysis}

Summary statistic are presented as mean and standard deviation (SD). The $x^{2}$ test and Fisher exact test was used to compare categorical variables, and the t-test and the Mann-Whitney U-test were used to compare continuous variables. $p$ values $>0.05$ were considered as statistically significant. The statistical analyses were performed with IBM SPSS Statistics for Windows, version 22 (IBM Corp., Armonk, NY, USA).

\section{Results}

Five university hospitals used different methods for CDI diagnostics (Table 1). In the study hospital (OUH) district the incidence of $\mathrm{CD}$ findings per 100,000 inhabitants (based on national register) was higher compared with other university hospital districts (159 vs. 70-84).

In 2013, totally 6948 stool samples for CD toxin determination were examined in the OUH laboratory (Nordlab). From 1015 positive samples (14.5\% of all), 261 different patients with 391 positive findings were treated in the study hospital. The main characteristics of the study population are shown in Table 2. The mean age was 65 yrs. (range 16-102), while $37 \%$ were older than

Table 1 Comparison of the incidence of Clostridium difficile cases per 100,000 inhabitants in five university hospital districts in Finland basing on the national register in the year 2013

\begin{tabular}{|c|c|c|c|c|}
\hline Hospital district & Population (million) & $\begin{array}{l}\text { Number of } C D \text { cases in } \\
\text { national register }\end{array}$ & $\begin{array}{l}\text { Incidence per 100,000 } \\
\text { inhabitants }\end{array}$ & Test method \\
\hline Hospital A & 1.6 & 1173 & 73 & $\begin{array}{l}\text { F-Cldi culture } \\
\text { and EIA }\end{array}$ \\
\hline Hospital B & 0.5 & 368 & 70 & $\begin{array}{l}\text { F-CldiAg + F-Cldi } \\
\text { culture }\end{array}$ \\
\hline Hospital C & 0.5 & 420 & 84 & $\begin{array}{l}\text { F-Cldi culture } \\
\text { and GDH }\end{array}$ \\
\hline Hospital D & 0.4 & 638 & 159 & F-CldTNhO \\
\hline Hospital E & 0.2 & 168 & 84 & NAAT for tcdB \\
\hline
\end{tabular}

$F$ faecal, Cldi Clostridium difficile, ElA enzyme immuno assay, $A g$ antigen, GDH glutamate dehydrogenase assay, NAAT nucleid acid amplification test, tcdB toxin B gene, NhO nucleid acid assay 
Table 2 Main characteristics of adult CD patients $(N=261)$ treated in Oulu University Hospital in 2013

\begin{tabular}{ll}
\hline Variable & \\
\hline Gender (M/F) & $125 / 136(48 / 52 \%)$ \\
Age (yrs, mean, SD) & $64.8(19.1)$ \\
Department ${ }^{\mathrm{a}}$ (medicine/surgery) & $192 / 69(74 / 26 \%)$ \\
Positive CD culture & $32(12 \%)$ \\
Genotyping & $10(3.8 \%)$ \\
Diabetes & $58(22 \%)$ \\
Immunosuppressive & $76(29 \%)$ \\
IBD & $7(2.7 \%)$ \\
Chronic renal disease & $18(6.9 \%)$ \\
Preceding antibiotics & \\
Cephalosporins & $127(48 \%)$ \\
Other beta-lactams & $102(39 \%)$ \\
Fluoroquinolones & $37(14 \%)$ \\
Clindamycin & $20(7.7 \%)$ \\
Vancomycin & $27(10 \%)$ \\
Antifungals & $10(3.8 \%)$ \\
Other antibiotics & $19(7.3 \%)$ \\
No data & $34(13 \%)$ \\
\hline
\end{tabular}

${ }^{a}$ The specialty where the patient was treated. In surgery gynaecology, otorhinolaryngology and ophthalmology are included. ${ }^{b}$ Chronic inflammatory bowel disease. $C D$ Clostridium difficile

75 yrs., $22 \%$ were diabetic and $29 \%$ immunocompromised (defined as a malignant disease or an immunosuppressive disease or treatment). Chronic inflammatory bowel disease was uncommon. Surprisingly, diarrhea as a symptom the day the stool sample was collected was mentioned in the patient documents in only $58 \%$ of cases (no data in $28 / 26111 \%$ of cases).

The treatment for the first episode of CDI was as follows: metronidazole in 167 cases (64\%), per oral vancomycin in $42(16 \%)$ and metronidazole and vancomycin combination therapy in 10 (3.9\%). Fidaxomicin was given in four cases (1.6\%). In 22 cases (8.4\%) the only treatment was the cessation of the ongoing antibiotics and in 16 (6.1\%) no data was found. In two situations, fecal transplantation was performed and in one case of toxic megacolon colectomy was performed. Recurrent infection was seen in 58 patients $(22 \%)$. The number of recurrences was one in 34 patients, two in 14 , three in six, four in two and five recurrences in two cases. There was no difference in the risk of recurrent infection between those treated with metronidazole or vancomycin $(35 / 167,27 \%$ vs. $13 / 42,31 \% p=0.17)$.

The all-cause 30 day mortality rate of the patients was $7.3 \%$ The majority of the cases (74\%) were identified in the department of medicine, while the mortality rate was more than two times higher among surgical cases $(13.0 \%$ vs. $5.2 \%, p=0.03)$. The number of recurrences was significantly higher among survived CD patients $(p=0.003)$.

Ribotype analysis was performed in only 17 cases. Ribotype 178 was the most common, seven cases following 023 (four cases), 126 (two cases), and 014, 035, 045 and 143 (each one case). No ribotype 027 cases were identified.

As Table 3 shows, there was no increase either in the CD cases treated in the OUH in 2009-2016 or in the proportion of positive $\mathrm{CD}$ findings per all studied samples.

\section{Discussion}

Our results show that the incidence of $C D$ cases varied in five university hospital districts probably due the different diagnostic methods. Based on data from the OUH laboratory, the yearly numbers of $\mathrm{CD}$ cases treated in the OUH were quite constant during the years 20092016. In our one-year cohort, the number of recurrence was $22 \%$ and the 30 day all-cause mortality rate $7.3 \%$. It is also noteworthy that the mortality among the patients treated in surgical wards was significantly higher than among the patients treated in medical wards. Because of the figures isallcause mortality we cannot exclude the contribution of the underlying diseases.

There may be several explanations why our hospital district had highest incidence of CD infections. We have used PCR-based diagnostics since the autumn 2010 whereas three other university hospitals used culture method when the survey was performed. In a population-based surveillance, the adoption of NAAT instead of toxin enzyme assay for diagnosis of CDI showed increase of $43-67 \%$ in CDI incidence [12]. In a European review, the mean sensitivity of the PCR based methods was $86 \%$ and the mean specificity 97\%, both much higher than with other methods [13]. According to the current guidelines two or three steps algorithm should be use for diagnosing CDI

Table 3 Number of Clostridium difficile patients treated in the Oulu University Hospital in 2009-2016

\begin{tabular}{lllll}
\hline Year & $\begin{array}{l}\text { Number of } \\
\text { patients } \\
\text { with positive } \\
\text { samples }\end{array}$ & $\begin{array}{l}\text { Number of } \\
\text { patients with } \\
\text { negative samples }\end{array}$ & $\begin{array}{l}\text { Number of } \\
\text { all patients } \\
\text { with samples } \\
\text { taken }\end{array}$ & $\begin{array}{l}\text { The percentage } \\
\text { of positive } \\
\text { samples of all } \\
\text { samples }\end{array}$ \\
\hline 2009 & 239 & 1103 & 1342 & 17.8 \\
2010 & 221 & 1190 & 1411 & 15.7 \\
2011 & 263 & 2376 & 2639 & 10.0 \\
2012 & 231 & 1313 & 1544 & 15.0 \\
2013 & 261 & 1547 & 1808 & 14.4 \\
2014 & 287 & 1551 & 1838 & 15.6 \\
2015 & 267 & 1507 & 1774 & 15.1 \\
2016 & 230 & 1586 & 1816 & 12.7 \\
\hline
\end{tabular}

Also the yearly number of all and negative faecal samples and proportion of positive samples are shown 
instead of stand-alone test for toxin gene detection by NAAT or PCR $[14,15]$. It is possible that some of the cases detected by NAAT or PCR represent colonization rather than true infection, given that NAAT detects the presence of the organism but not necessarily, if it is disease-causing [16]. The rate of asymptomatic colonization in non-hospitalized adults is estimated to be $2 \%$ and up to $26 \%$, in those with health care exposures [17, 18]. Asymptomatic colonization may explain some of our CD findings, because only $58 \%$ cases had diarrhea marked as a previous symptom, leaving a doubt that even almost $40 \%$ of the samples had no indication. Actually, this is against the current guidelines, which support to test only unformed stool samples $[14,15,19]$. One-step procedure performed by a highly sensitive method demands appropriate sample collection. Unless adjustments based on methodology and population prevalence are considered, hospitals participating in public reporting of CDI rates will be at a disadvantage for performing the most sensitive testing methodologies $[1,16]$. So, the methodological differences between regional laboratories hamper the comparisons between the hospital districts. One reason for differences in five university hospitals may also due to problems with the data collection from the hospital districts to the national CDI register.

Overall use of antibiotic agents is associated with a 3 -fold increased risk of community-acquired CDI, but it has also been detected substantial variation in risk associated with different antimicrobial classes, with fluoroquinolones and clindamycin associated with the greatest enhancement of risk [20]. In our study showed that most often cephalosporins (49\%), other $\beta$-lactams $(45 \%)$ and fluoroquinolones (14\%) were used before CDI. In our material $7.7 \%$ were using clindamycin previously, even though it has been previously described as a high-risk antibiotic [20]. That cephalosporins were used most often preceding CDI reflects our guidelines, where cefuroxime, a second-generation cephalosporin, is the first line antibiotic in several diagnoses, like community acquired pneumonia, pyelonephritis and community acquired bacteremia.

In our study mean recurrence rate was $22 \%$. Recurrence rates for health care-associated CDI have been reported to vary from 5 to $50 \%$, with an average of $20 \%$ [21, 22]. Also higher recurrence rates have been variously reported, from $3 \%$ to even $65 \%[23,24]$. There are three risk factors, which predict the risk for recurrent CDI: age $>65$ years, severe underlying disease and continued use of antibiotics for non-CDI infections [25]. In our study mean age was 64.8 years, at least $61 \%$ had a significant comorbidity and $85 \%$ had a continued use of antibiotics for non-CDI infections.

Cochrane review in 2013 states on CDI treatment that current evidence leads to uncertainty whether mild CDI needs to be treated [26]. The studies provide little evidence for antibiotic treatment of severe CDI as many studies excluded these patients. Improvement of the patient's clinical condition and prevention of spread of $C$. difficile infection to the other patients should be the two goals of therapy. Therefore an antibiotic that brings both symptomatic cure and bacteriologic cure [25] is to be chosen. In our study, the treatment options mimicked the existing guidelines, $64 \%$ were treated with metronidazole, $16 \%$ with peroral vancomycin, metronidazole and vancomycin combination therapy was used in $3.9 \%$ of cases. Fidaxomicin was used only in four cases, but it has been reported that fidaxomicin provides improved sustained cure rates in patients with CDI compared with vancomycin [27]. There were no statistical differences in treatment options between survivors and fatal cases in 30-day all case mortality. Two patients had fecal microbiota transplantation that year, since then its use has widened significantly in our university hospital district.

Our analyses have limitations. Collecting data retrospectively always has its limitations in the form of missing data. In addition, the case definition relied solely on positive results on $C$. difficile toxin or molecular assay because diarrhea is usually poorly documented in charts and existing guidelines for laboratory practice recommend $C$. difficile testing only on unformed stools. Laboratories should adopt stricter policies to reject formed stools when transitioning to NAAT.

\section{Conclusions}

Our PCR-based approach gave higher incidence of CD infections than other four university hospital districts in Finland. However, the number of the cases treated in the OUH remained quite stable and the main clinical characteristics of the cohort were in harmony with earlier literature. The quality of stool samples needs more critical evaluation in our hospital because almost $40 \%$ of the samples were formed stools, i.e. they actually did not represent diarrhea and might have therefore no indication for $\mathrm{CD}$ analysis.

\section{Abbreviations \\ A (TcdA): Toxin A; B (TcdB): Toxin B; CDI: Clostridium difficile infection; CDT: Clostridium difficile transferase; GTPases: Glucosyltranspherases; NAAT: Nucleic acid amplification test; NIDR: the National Infectious Diseases Register; OUH: Oulu University Hospital; PCR: Polymerase chain reaction}

\section{Acknowledgements}

Not applicable.

\section{Funding}

Grant from Astellas Pharma (number T74263). The funding body did not have any role in the design of this study, data collection or analysis and interpretation of the data. One of the authors (PY) was on the study leave when writing the preliminary manuscript.

Availability of data and materials

All data generated or analysed during this study are included in this published article. It can also been asked from the corresponding author.

Authors' contributions

MM-V participated in the design of the study and acquisition and analysis of data and drafted the manuscript. HK and PY participated in the design of the study and analysis of data and drafted the manuscript. All of the authors read and approved the final draft of the manuscript. 


\section{Ethics approval and consent to participate}

The study protocol was approved by the Ethics Committee of Oulu University Hospital. Because the study was epidemiological without any interventions, the requirement for informed consent was waived.

\section{Consent for publication}

Not applicable.

\section{Competing interests}

The authors declare that they have no competing interests.

\section{Publisher's Note}

Springer Nature remains neutral with regard to jurisdictional claims in published maps and institutional affiliations.

\section{Author details}

${ }^{1}$ Research unit of Internal Medicine, Oulu University Hospital and University of Oulu, Oulu, Finland. ${ }^{2}$ Department of Infection Control, Oulu University Hospital, Box PL 20 FIN-90029 OYS, Oulu, Finland.

Received: 6 July 2018 Accepted: 26 December 2018

Published online: 11 January 2019

\section{References}

1. Leffler DA, Lamont JT. Clostridium difficile infection. N Engl J Med. 2015;372: 1539-48. https://doi.org/10.1056/NEJMra1403772.

2. Kuehne SA, Cartman ST, Heap JT, Kelly MT, Cockayne A, Minton NP. The role of toxin a and toxin B in Clostridium difficile infection. Nature. 2010;467: 711-3. https://doi.org/10.1038/nature09397.

3. Rupnik M, Grabnar M, Geric B. Binary toxin producing Clostridium difficile strains. Anaerobe. 2003;9:289-94. https://doi.org/10.1016/j.anaerobe.2003.09.002.

4. Sun $X$, Hirota SA. The roles of host and pathogen factors and the innate immune response in the pathogenesis of Clostridium difficile infection. Mol Immunol. 2015;63:193-202. https://doi.org/10.1016/j.molimm.2014.09.005.

5. Martínez-Meléndez A, Camacho-Ortiz A, Morfin-Otero R, Maldonado-Garza HJ, Villarreal-Treviño L, Garza-González E. Current knowledge on the laboratory diagnosis of Clostridium difficile infection. World J Gastroenterol. 2017;23:1552-67. https://doi.org/10.3748/wjg.v23.i9.1552.

6. Evans CT, Safdar N. Current Trends in the Epidemiology and Outcomes of Clostridium difficile Infection. Clin Infect Dis. 2015;60(Suppl 2):S66-71. https://doi.org/10.1093/cid/civ140.

7. Bignardi GE. Risk factors for Clostridium difficile infection. J Hosp Infect. 1998:40:1-15.

8. Desai K, Gupta SB, Dubberke ER, Prabhu VS, Browne C, Mast TC. Epidemiological and economic burden of Clostridium difficile in the United States: estimates from a modeling approach. BMC Infect Dis. 2016;16:303. https://doi.org/10.1186/s12879-016-1610-3.

9. Mentula S, Kotila SM, Lyytikäinen O, Ibrahem S, Ollgren S, Virolainen A. Clostridium difficile infections in Finland, 2008-2015: trends, diagnostics and ribotypes. Eur J Clin Microbiol Infect Dis. 2017;36:1939-45. https://doi.org/10. 1007/s10096-017-3017-5.

10. Kanerva M, Ollgren J, Voipio T, Mentula S, Lyytikäinen O. Regional differences in Clostridium difficile infections in relation to fluoroquinolone and proton pump inhibitor use, Finland, 2008-2011. J Infect Dis. 2015;47: 530-5. https://doi.org/10.3109/23744235.2015.1026933.

11. https://thl.fi/fi/tilastot-ja-data. National Institute for Health and Welfare, Helsinki, Finland.

12. Gould CV, Edwards JR, Cohen J, Bamberg WM, Clark LA, Farley MM, Johnston H, Nadle J, Winston L, Gerding DN, McDonald LC, Lessa FC. Effect of Nucleid acid amplification testing on population-based incidence rates of Clostridium difficile infection. Clin Infect Dis. 2013:57:1304-7. https://doi.org/10.1093/cid/cit492.

13. Crobach MJ, Dekkers OM, Wilcox MH, Kuijper EJ. European society of clinical microbiology and infectious diseases (ESCMID): data review and recommendations for diagnosing Clostridium difficile-infection (CDI). Clin Microbiol Infect. 2009;15:1053-66. https://doi.org/10.1111/j. 1469-0691.2009.03098.x.

14. Crobach MJT, Planche T, Eckert C, Barbut F, Terveer EM, Dekkers OM, Wilcox $\mathrm{MH}$, Kuijper EJ. European Society of Clinical Microbiology and Infectious Diseases: update of the diagnostic guidance document for Clostridium difficile infection. Clin Microbiol Infect. 2016;22:S63-81. https://doi.org/10. 1016/j.cmi.2016.03.010
15. McDonald LC, Gerding DN, Johnson S, Bakken JS, Carroll KC, Coffin SE, Dubberke ER, Garey KW, Gould CV, Kelly C, Loo V, Sammons JS, Sandora TJ, Wilcox MH. Clinical practice guidelines for Clostridium difficile infection in adults and children: 2017 update by the Infectious Diseases Society of America (IDSA) and Society for Healthcare Epidemiology of America (SHEA). Clin Infect Dis. 2018;66:987-94. https://doi.org/10.1093/cid/ciy149.

16. Nagy E. What do we know about the diagnostics, treatment and epidemiology of Clostridioides (Clostridium) difficile infection in Europe? J Infect Chemother. 2018;24:164-70. https://doi.org/10.1016/j.jiac.2017.12.003.

17. Lessa FC, Mu Y, Bamberg WM, Beldavs ZG, Dumyati GK, Dunn JR, Farley MM, Holzbauer SM, Phipps EC, Wilson LE, Winston LG, Cohen JA, Limbago BM, Fridkin SK, Gerding DN, McDonald LC. Burden of Clostridium difficile infection in the United States. N Engl J Med. 2015;372:825-34. https://doi. org/10.1056/NEJMoa1408913.

18. Slimings C, Riley TV. Antibiotics and hospital-acquired Clostridium difficile infection: update of systematic review and meta-analysis. J Antimicrob Chemother. 2014;69:881-91.

19. Surawicz CM, Brandt $L$, inion DG, Ananthakrishnan AN, Curry SR, Gilligan PH, McFarland LV, Mellow M, Zuckerbraun BS. Guidelines for diagnosis, treatment, and prevention of Clostridium difficile infections. Am J Gastroenterol. 2013;108:478-98. https://doi.org/10.1038/ajg.2013.4.

20. Brown KA, Khanafer N, Daneman N, Fisman DN. Meta-analysis of antibiotics and the risk of community-associated Clostridium difficile infection. Antimicrob Agents Chemother. 2013;57:2326-32.

21. Aslam S, Hamill RJ, Musher DM. Treatment of Clostridium difficile-associated disease: old therapies and new strategies. Lancet Infect Dis. 2005;5:549-57.

22. Eyre DW, Walker AS, Wyllie D, Dingle KE, Griffiths D, Finney J, O'Connor L, Vaughan A, Crook DW, Wilcox MH, Peto TE. Predictors of first recurrence of Clostridium difficile infection: implications for initial management. Infections in Oxfordshire Research Database. Clin Infect Dis. 2012;55(Suppl 2):577-87. https://doi.org/10.1093/cid/cis356.

23. Johnson S. Recurrent Clostridium difficile infection: a review of risk factors, treatments, and outcomes. J Inf Secur. 2009:58:403-10.

24. Khanna S, Pardi DS, Aronson SL, Kammer PP, Orenstein R, St Sauver JL, Harmsen WS, Zinsmeister AR. The epidemiology of community-acquired Clostridium difficile infection: a population-based study. Am J Gastroenterol. 2012;107:89-95. https://doi.org/10.1038/ajg.2011.398.

25. Kelly CP. Can we identify patients at high risk of recurrent Clostridium difficile infection? Clin Microbiol Infect. 2012;18(Suppl 6):21-7.

26. Nelson RL, Kelsey P, Leeman H, Meardon N, Patel H, Paul K, Rees R, Taylor B, Wood E, Malakun R. Antibiotic treatment for Clostridium difficile-associated diarrhea in adults. Cochrane Database Syst Rev. 2011:CD004610. https://doi. org/10.1002/14651858.CD004610.pub4.

27. Louie TJ, Miller MA, Mullane KM, Weiss K, Lentnek A, Golan Y, Gorbach S, Sears P, Shue YK. OPT-80-003 clinical study group. Fidaxomicin versus vancomycin for Clostridium difficile infection. N Engl J Med. 2011;364:422-31. https://doi.org/10.1056/NEJMoa0910812.

Ready to submit your research? Choose BMC and benefit from:

- fast, convenient online submission

- thorough peer review by experienced researchers in your field

- rapid publication on acceptance

- support for research data, including large and complex data types

- gold Open Access which fosters wider collaboration and increased citations

- maximum visibility for your research: over $100 \mathrm{M}$ website views per year

At $\mathrm{BMC}$, research is always in progress.

Learn more biomedcentral.com/submissions 